\title{
E-CARE CO-ORDINATION: AN INCLUSIVE COMMUNITY-WIDE HOLISTIC APPROACH
}

\author{
M. McKeon Stosuy, B.R.M. Manning, B.R. Layzell \\ European Federation for Medical Informatics: Working Group on Planning and Modelling in \\ Healthcare
}

Abstract: Substantial demographic changes, while centred on the number of elderly in the developed world, are forcing a radical re-evaluation of how to deliver care more effectively to all, including those with chronic conditions or disabilities. Optimizing and co-ordinating complete multi-disciplinary, multi-agency endto-end service processes are seen as key to this. As real-time access to comprehensive care records and relevant knowledge systems is a critical enabler, the paper explores the closer integration of the patient experience as an "expert" knowledge source rather than just an "informed" one. It highlights the dependency on the effective management of change will have on such a major transformation.

Key words: One-stop-shops, customer relationship management [CRM], electronic healthcare/social care records [EHR], knowledge acquisition and management, genomaps, virtual enterprises, end-to-end processes.

\section{INTRODUCTION - THE DEMOGRAPHIC IMPERATIVE}

Governments across much of the developed world are having to respond to growing impacts of an ageing population. As forecasts all show a steep rise in the percentage of the population who are older than 65 years old doubling to close to $40 \%$ by the middle of the century (Commission of the European Communities, 2004) the pattern of service demand is likely alter radically. 
In addition to the inevitable increase in acute care episodes there will be substantial growth in the number patients with chronic conditions needing a wide spectrum of care to be delivered within the community. The overall effect will almost certainly be a major shift in the balance of service provision towards chronic care.

Even from these crude estimates it is evident that current models of care are wholly unsustainable on resource grounds alone. This suggests that endto-end care processes will have to be streamlined to optimize carer input through increasing use of assistive technologies.

This in turn will mean a substantial revision away from the present split separating clinical from "social" interventions to a more "holistic" one. While remaining an essential key component, medicine will need to cede elements of its traditionally care controlling role and concentrate more on maximizing use of its professional expertise.

Early moves in this direction can already be seen in the use of multidisciplinary team approaches in acute care both in hospitals and the community. Exactly how this will evolve will not only on depend how the various professions adapt and re-balance their responsibilities, but also on how rapidly new enabling technologies emerge and how acceptable they become to those in need.

\section{E-HEALTHCARE}

Current initiatives (Commission of the European Communities, 2001, and Braun et al, 2003) in the e-health arena have tended to split between acute care, which is generally centred on shared life-long Electronic Health Records and transfer of clinical information; and "one-stop-shop" community Resource Centres where people can turn for information, advice and action across a wide spectrum of Health and Welfare/Human Services support.

While the emphasis on information requirements and flows differs in detail between them, they share the common need for access to patient history data as well as to relevant knowledge and/or expertise. This paper focuses on the latter area and its development potential. 


\section{AGEING AND DISABILITY COMMUNITY RESOURCE CENTRES}

Current "one-stop-shop" initiatives tend to follow commercial practice presenting a centralized front office interfacing with the citizen (McKeon Stosuy and Manning, 2005). This is generally designed around a multiservice bureaux split between a direct face-to-face contact facility and a call centre, often using somewhat rudimentary processes and information systems.

Figure 1. Multi-mode, Multi Agency Service Coordination Model

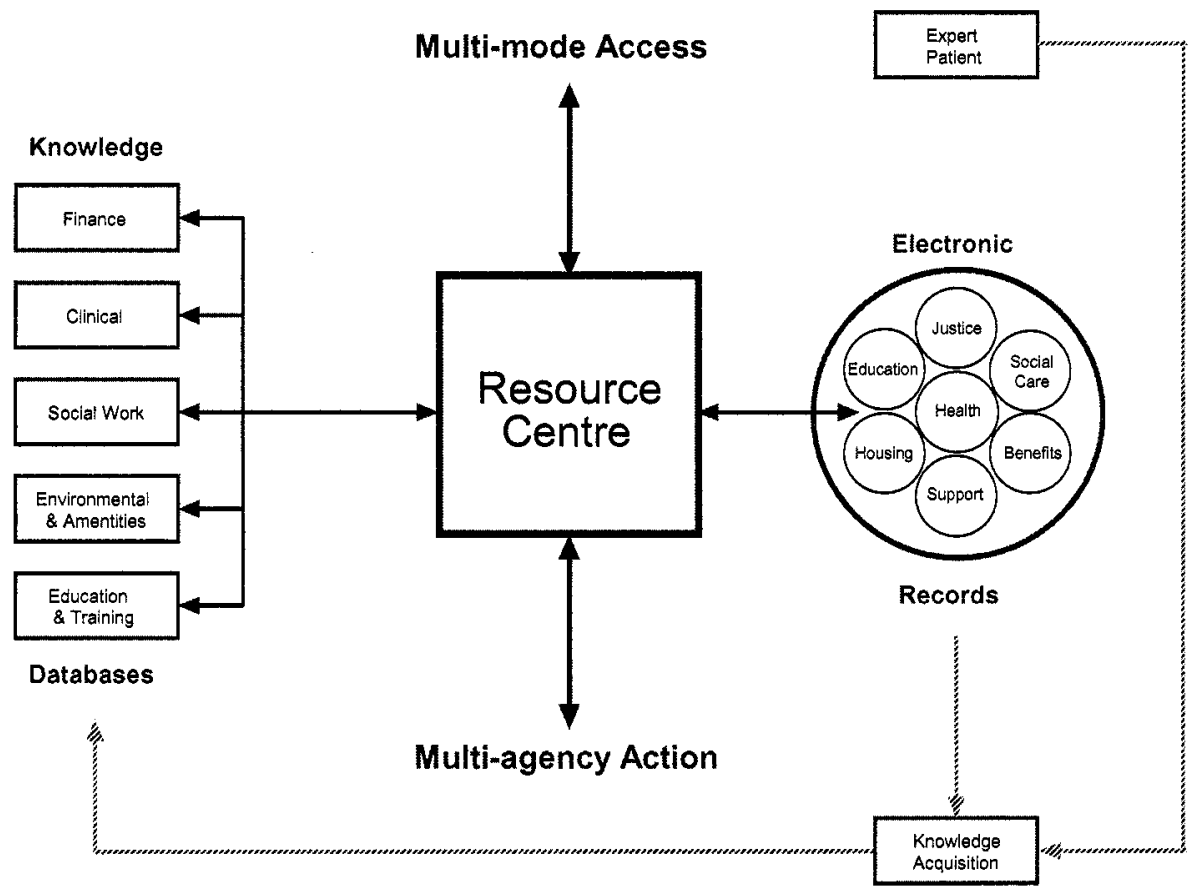

The proposed Resource Centre concept (Manning et al, 2004) is outlined in Figure 1 above. In order to serve the widest possible range of clients/patients, it needs to span the complete spectrum of communications media ranging from direct personal contact through to current and emergent digital technologies. Similarly it will have to resolve and co-ordinate action on anything from the seemingly trivial to immensely complex long-term 
issues that involve a multiplicity of agencies and professions (Stosuy. and Eaglin, 1999).

An intrinsic aspect of these responses will be the need for rapid access to appropriate multi-agency background historic client/patient data together with the most relevant expertise and supporting knowledge. As currency and accuracy of information from both sources will be vital to ensuring that correct action is taken and right advice and guidance is given, the underlying information systems will need to maintained and validated in real-time? Moreover these systems will need to be fully secure both to protect patient confidentiality and to conform to data protection legislative constraints.

In the longer term the store of appropriate knowledge will need to accommodate the acquisition, validation, indexing and accessible storage of information to be gleaned from "expert patient" groups in addition to that derived from research.

Figure 2. Generic Resource Centre

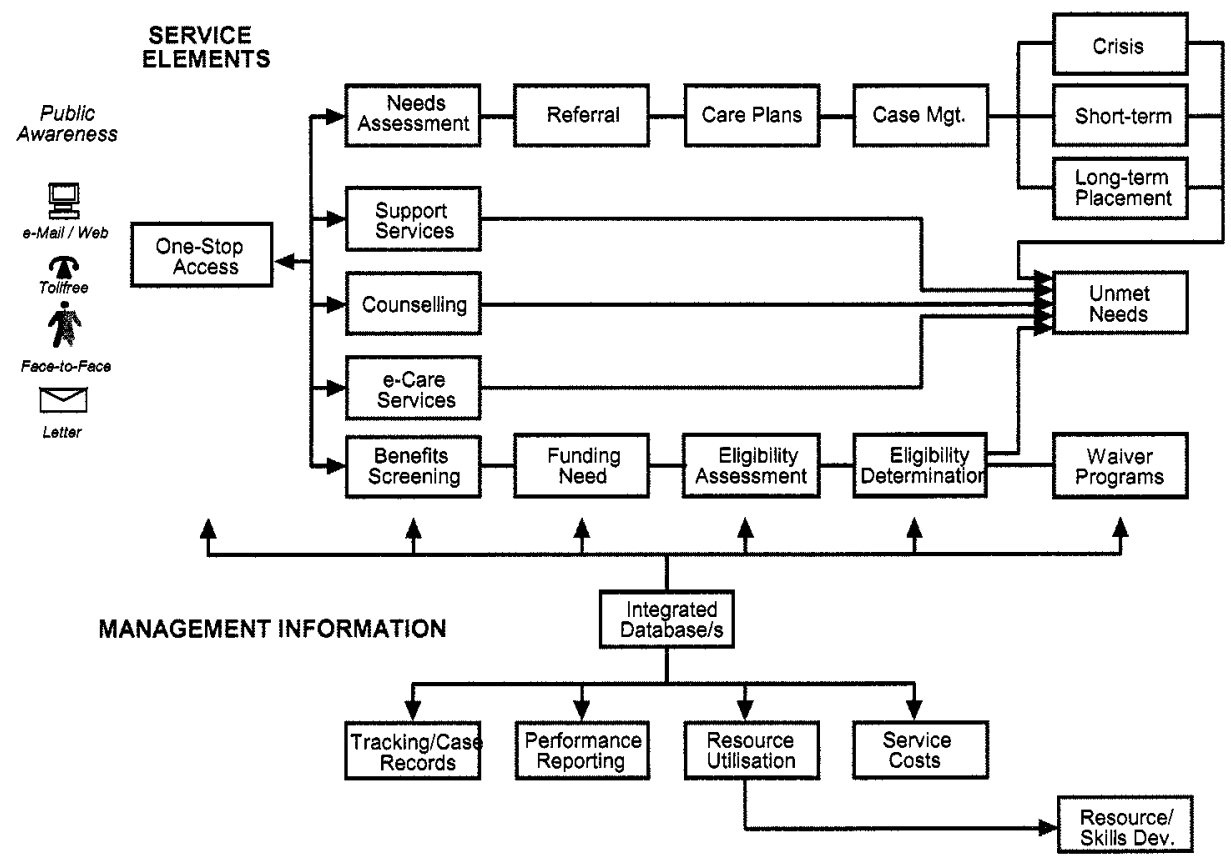


While the scope of the services provided will no doubt continue to evolve steadily with time, some of the more common service features and management information requirements are shown above in Fig 2.

The bulk of the workload will almost inevitably focus on case coordination action through the usual sequence of assessment, planning and delivery, frequently together with one or more of the other streams shown. Due to age or disability many cases will involve some measure of financial screening and subsequent securing of necessary support. With many cases involving access to multi-agency records this brings with it the problem of identity validation due to the lack of agreed standards and differing indexing and registration referencing.

From a management perspective the complete set of end-to-end processes will need to be properly underpinned not only with appropriate operational support systems and communications infrastructure, but also with relevant cross-agency service delivery performance information. Within this latter context, shortfalls in terms of unmet needs, resources, efficiency, effectiveness and quality will be a major priority in ensuring that high standards are maintained as the changing demographic situation begins to impact service delivery.

\section{E-CARE IN THE COMMUNITY}

As e-Care becomes an increasingly available option that enables patients/clients to maintain an independent lifestyle through the use of a combination of monitoring and assistive technologies, it will introduce an additional "care watch" role within the Resource Centre. This will provide continuous monitoring of its patients/clients for any abnormal or untoward clinical, lifestyle or environmental condition coupled with the ability to call out/deploy resources as necessary in response to their professional assessment of the urgency and type of need. 
Figure 3. e-Care Support Service Features (Barlow et al 2003)

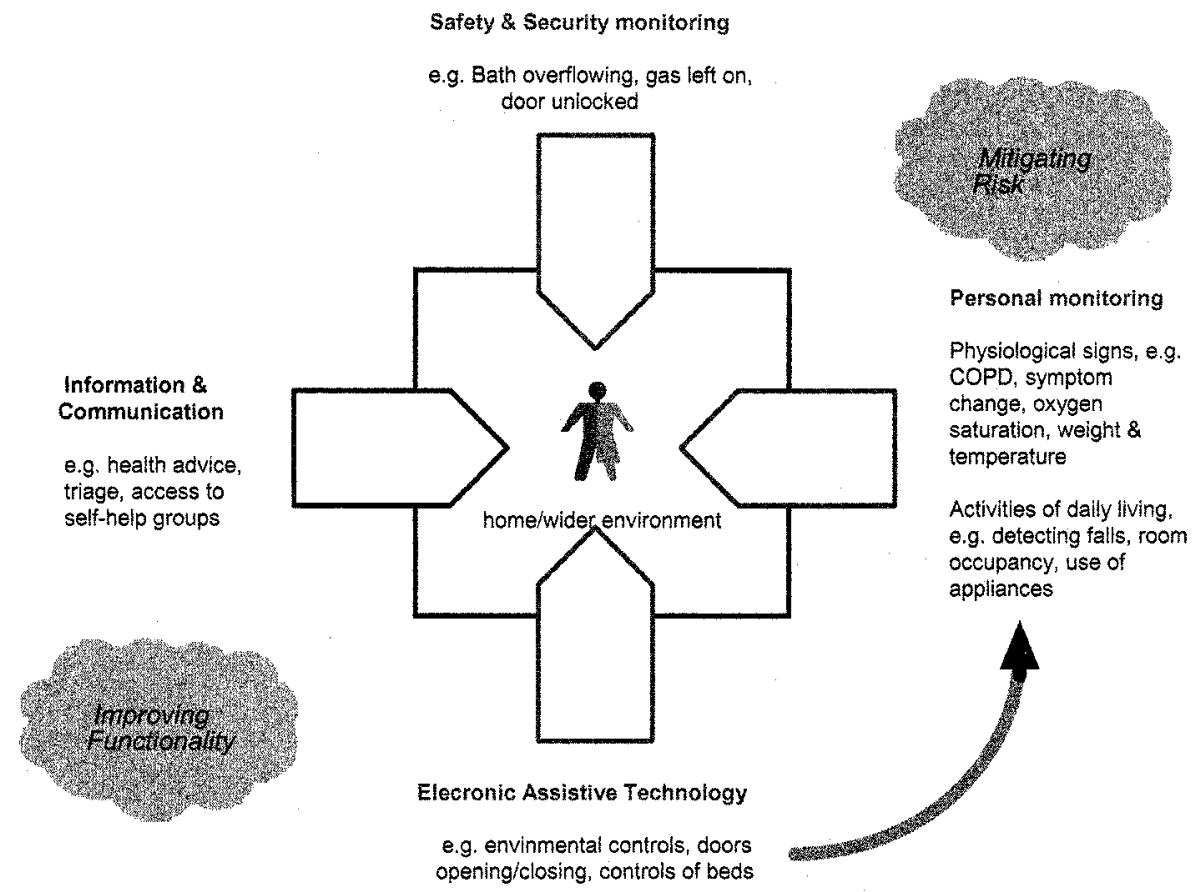

Within the overall aim of maximizing its patient's/client's capacity for continued independent living, e-Care will also provide a two way link to the Resource Centre for advice and help as well as to support groups all targeted to reduce isolation and build "virtual communities" of shared interests.

In addition to the networked support services shown in Fig 3 above, an evolving range of autonomous closed loop and interlinked Assistive Technologies will not only fill gaps left by the shortfall in available carers, but also provide increasing functionality to all concerned. As indicated this will steadily extend to combine elements of the "Smart House" and the "Hospital at Home" into a single pro-active support system that optimizes the living environment to the needs of its users (DTI/PERA, 2004). Besides providing much enhanced functionality beyond existing building services, it will also enhance ambulatory capabilities in a variety of ways including Bluetooth linked wearable monitoring devices, advanced prosthetic devices, mobility aids, and sensory/communication aids. 


\section{KNOWLEDGE EXTRACTION SYSTEM}

For Resource Centres to be fully effective, immediate access to information that is current and correct is critically important. This applies equally to comprehensive case data and to multi-disciplinary domain knowledge, the lack of it will rapidly devalue the system and alienate users.

Leading-edge technology (Audentify, 2003) now offers a way to move towards dynamic service updating with input from users and care service agencies all routed through a single Portal as shown in Fig. 4 below. Face-toface and phone call audio data can be automatically transcribed in a common text format, together with incoming letters, and merged with all other communications traffic.

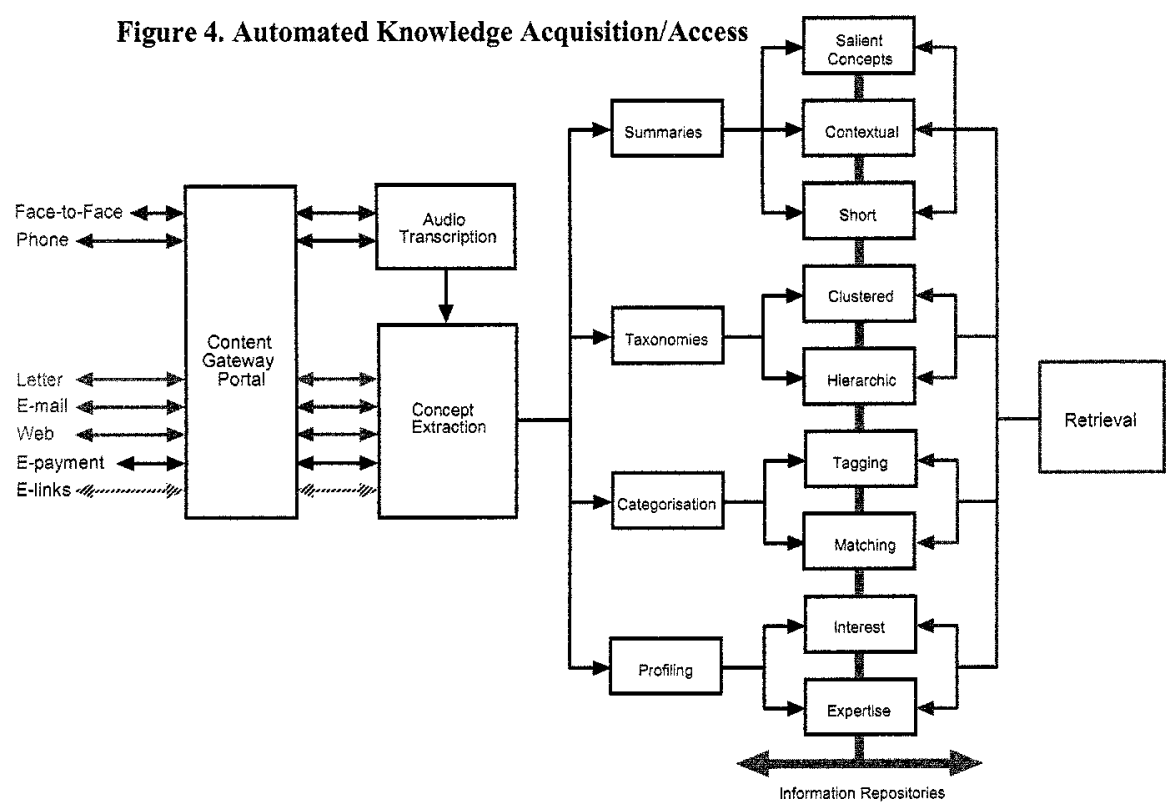

In addition to onward transmission of all data to its appropriate destinations, the total content can be filtered through an on-line knowledge 
extraction process. This analyzes and sorts all throughput into logical concept groups and then classifies the content as required into:

- Summaries: compact content down to a more manageable scale that assists rapid assimilation, recognition of recurrent themes and trends, as well as adding valuable cues to hidden key contextual information

- Taxonomies: minimize the work involved in organizing content for intuitive navigation and provide a useful aid to recognition of emergent patterns and trends.

- Categories: enable hypertext and other linkage mechanisms required to support rapid searches.

- Profiles: provide search criteria for interest groups and expertise holders.

\section{THE "EXPERT" PATIENT - CONCEPT AND CONTEXT}

The concept of the expert patient is not a new phenomenon, but one that has matured over decades. Latterly it has begun to move out of the shadows as the recognition of the swelling numbers of the aged who already do, or shortly will, present ever more cases with chronic conditions.

While the patient has traditionally been seen as the "subject of care", this also has begun to change from an "arms-length" position to one more directly involved in the care decision process. This is particularly true of some chronic conditions where the role of the "expert patient" is effectively integrated within the care team, as circumstance has often made them the more knowledgeable member in terms of what works for them.

In the UK the concept of the expert patient (UK Department of Health, 2001) recognizes that clinicians often accept that "my patient understands their disease better than I do" and that as such patients have too long been an untapped resource. However their focus is more on developing the "informed" patients as key decision-makers in self-management programmes. rather than as true "experts" adding to the sum of clinical knowledge of their condition.

This can also be particularly true for disabled people, where the nature of their disability may pose problems and even a very real risk of harm of through inappropriate medical, nursing or therapeutic interventions due to the specific characteristics of their physiology. In such circumstances the patient is revealed as the real expert who often has to lead and "teach" 
unfamiliar health professionals in alternative methods of diagnosis, treatment, therapy and care.

There is evidence that some disabled people who, while not ill, often find that the nature of their disability can be a barrier to getting the proper treatment when they are actually ill. Relatively simple clinical procedures, such as, taking a blood sample, giving an injection, etc., often become exceedingly complicated or even dangerous with such disabilities as e.g. spina bifida; congenital organ or musculo-skeletal or limb deficiencies. Inappropriate medical or nursing intervention through lack of specialist expertise can all too easily worsen matters however well intentioned this is.

In this context there is an evident need to accept differences between the "informed" and the true "expert" and take the concept a stage further by seeking ways to secure and formalize this additional body of knowledge. The evolution of this approach, backed by easily accessible information and assistive technologies may provide a solution to the demographic dilemma as it would allow elderly, disabled people and those suffering with chronic health conditions to maintain an independent lifestyle with less involvement from a waning pool of carers.

This transformation from "self informed" patients into recognisable "experts" will be undoubtedly a move in the right direction. However as their conditions have no definable clinical outcome it is all too easy for them to be referred to various other sources of help, e.g. self help groups or other voluntary agencies, and then, as of old, quietly slipping out of the national health care service ambit, as they do not fit the conventional medical model.

Initial moves to make access to information and services more coherent have led towards a "one-stop-shop" Contact/Advice Centre approach that combines new technology with traditional personal contact procedures. This evolution of e-care provision across the public and associated private and voluntary sectors has begun to lay the foundations for such interactive multidisciplinary team co-ordination with "expert patients" at its heart.

This would follow the established path of e-business development with the creation of "virtual utilities" linking the multiple agencies that are involved in providing health and welfare/human services into a single seamless entity. 


\section{THE EXPERT PATIENT - KNOWLEDGE ACQUISITION, TRANSFER AND INTEGRITY}

National health care providers have begun a series of programmes focusing on chronic disease self-management as a way to encourage and enable patients to develop the skills, abilities and coping strategies needed to improve their quality of life. This will also free up care resources needed to cope with increasing demand, as well as accepting that as many patient's "understand their disease better than clinicians" they should become key decision takers in the treatment process.

The knowledge that patients with chronic conditions have can be demonstrated to be far more than that which clinicians usually collect, as it includes considerable in-depth experience of the relative merits or otherwise of treatment practiced on them. Paradoxically little or no attempt has been made to collect, collate and disseminate this information within the clinical community at large.

Much of this probably stems from the traditional position of the patient as the passive "subject of care", rather than as an active contributor of unique practical expertise on optimum outcomes of different treatment processes. This is reinforced by the "womb-to-tomb" longitudinal Electronic Health Record which has no place for direct inclusion of the patient's own observations as an "expert".

The implication of this is that current records are incomplete, since they exclude insight into optimal treatment processes and outcome quality measures from the patient's point of view. However it poses the question of how to "qualify", and hence ensure the validity, quality and level of "expertise" presented by such patients. While traditional methods are obviously impractical and out of place, this is hardly a justifiable reason for rejecting such potentially valuable input.

Two fairly pragmatic options for collecting and analysing this information would seem to be by:

- Selection of suitably perceptive and articulate patients who would be given internet access to record their input to a secure site possibly as a blog.

- Creation of secure condition-specific patient membership only interactive self-help/support websites encouraging exchange of experience. 
As all input would be received via a web portal its evolving knowledge content could be extracted, analysed and categorised within metadata architectures (Layzell and Lindsay, 2004) using some of the more sophisticated knowledge acquisition techniques described below. This automatic process would have the advantage that, as the resulting aggregated data will remain anonymised it would not include references to the patient data sources.

In the former case the source data would be lodged either within the EHR along with other clinical input or within a separate record. Although the latter already exist in some countries in terms of chronic condition self-help information exchange websites, their open unregulated nature leaves them open to abuse. However this could be countered by re-creating them within a secure controlled access service, whose conformance to EU recommended codes of conduct and system "seals of approval" (Försstrom et al, 1999) would enhance trust and confidence.

In both cases membership would be clinician approved to ensure patient validity, and would have to conform both to national Data Protection legislation together with prevailing ethical and confidentiality constraints. This does not however remove the need for appropriate professional oversight to double-check and validate this input to obviate perceptual or factual errors creeping in and devaluing its content (Layzell, 2001).

\section{DELIVERING MEASURABLE BENEFITS}

However desirable acceptance of change across communities of users and providers may be, it is entirely dependent on gaining sufficient consensus across all the various organizations concerned, not only in terms of economies of scale and cost but also service quality concerns.

However as cost-benefit modelling is a major topic in its own right and the economic implications of this proposed approach have been addressed elsewhere (McKeon Stosuy and Manning, 2005), these issues have been considered beyond the scope of this paper. Instead the focus has been on the more qualitative, yet critical issue of system benefits realization that has all too frequently been the rock on which so many IT-driven initiatives have foundered

This needs to span all parties and individuals involved at every level, so that the potential benefits to be attained outweigh the pain and anguish likely 
to result. A major move to the proposed radically new e-care coordinated model will need to be tightly focused on delivering significant and easily recognisable measurable benefits to all.

The key issue is how to manage the transition from the current "as is" condition to the desired "to be" situation. This is considerably magnified when it involves creating a multi-agency "Virtual Enterprise", as outlined below in Figure 5.

\section{Figure 5. Benefits realization}

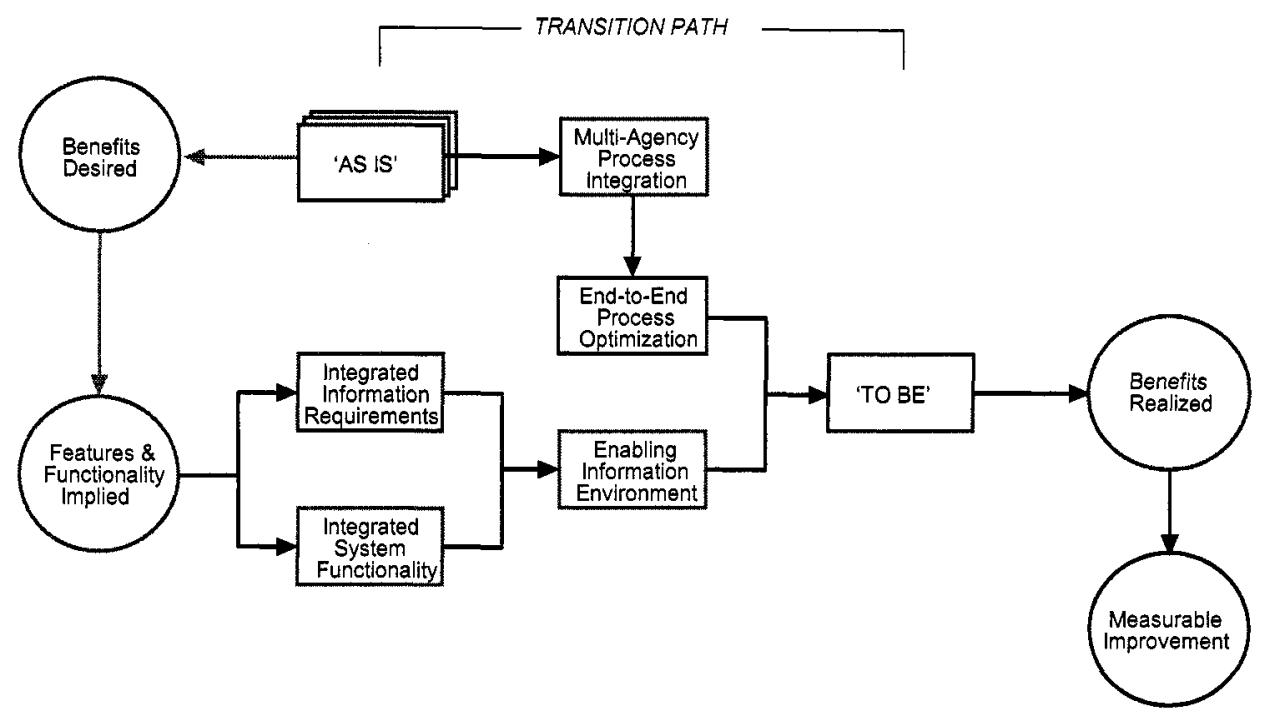

The re-configuration of the set of multiple and disconnected business processes into a single optimized end-to-end one requires the re-design of both business and enabling technology infrastructures to deliver the full "to be" functionality. Its implementation however has to be seen as a business transformation process involving significant change in professional cultures and working practice, which needs very careful management to ensure expectations are met and desired benefits are realized. 


\section{CONCLUSION}

The proposed approach brings together several strands of development in response to national and international initiatives that can potentially provide a generic model for the necessary sea-change in multi-disciplinary, multiagency care service provision that will be needed to address the demographic imperatives of this century. As part of this it recommends further evolution and formalisation of the concept of the Expert Patient into a valued source clinical knowledge, together with a better understanding of issues that are central to the success of such changes.

\section{REFERENCES}

Audentify. 2003. Audentify: Contact Centre Solutions - White Paper.

Braun, A; Constantelou A, Karounou V, Ligtoet A \& Burgelmann J-C., 2003. Prospecting ehealth in the context of a Eurpean Ageing Society; Quantifying and qualifying needs. Final report November 2003 IPTS/ESTO: Sevilla, Spain

Commission of the European Communities, 2001. [COM(2001) 723 Final]: The future of healthcare and care for the elderly: guaranteeing accessibility, quality and financial viability. $5 / 12 / 2001$

Commission of the European Communities, 2004. [COM(2004) 356]: e-Health - making healthcare better for European citizens: An action plan for a European e-Health Area

DTIPERA, 2004. Technology and Delivery of care for older people - a mission to Japan October 2004.

Försstrom J, et al, "1999. Towards Evaluation and Certification of Telematics Services for Health (TEAC-Health) - Key Recommendations" Commission of the European Union, DG XIII, Health Telematics Application Programme HC4101 Deliverable 8.1. University of Turku, ISBN 951-29-1577-4, Grafia Oy, Turku, Finland, 1999.

Layzell B R and Lindsay J, 2004. "Les informatiques sans frontiers - Health Informatics, Information Literacy, Social/Digital Inclusion, Globalization - and the role of health informaticians in knowledge transfer" "British Journal of Healthcare Computing \& Information Management" volume 21, number 6, July 2004

Layzell B R, 2001. "Globalisation and Development (a brief perspective in relation to access to health information)" presentation to IMIA Working Group 9 Workshop, Medinfo 2001, London see http://www.mifound.org/WG9/id18.htm

Manning, B.R.M., Lusted, M.J., Wong, BL.W., Budgen,, Y.M.2004.: E-Community Care: Bridging the Information Access Gaps. Healthcare Digital Libraries Workshop Proceedings University of Bath September 2004

Manning, B.R.M.. 2002 Consumer Relationship Management in the Community. International Consultants Guide. Feb 2002

McKeon Stosuy, M. and Manning, B.R.M., 2005. Joining Up e-Health \& e-Care Services: Meeting the Demographic Challenge. Administration on Aging: Aging \& Disability Resource Centers. www.aoa.gov/prof/aging_dis/aging_dis.asp

McKeon Stosuy, M and Manning. B.R.M. 2005. e-Health Symposium Proceedings of the $2^{\text {nd }}$ International Council of Medical and Care Compunetics Conference. Den Haag, Netherlands. June 2005. 
Stosuy, G.A. and Eaglin, J.P.1999. The Community Services Network: Creating an integrated Service Delivery Network - The Baltimore open systems laboratory model. New Technology in the Human Services Vol 12 1/2 87-98. NTHS 1999

UK Department of Health, 2001. The Expert Patient: A New Approach to Chronic Disease Management for the $21^{\text {st }}$ Century. Crown Copyright $248101 \mathrm{p} 15 \mathrm{k}$ AUG 01 (WOO) August 2001 see http://doh.gov.uk/healthinequalities 